\title{
Defective Tbx2-dependent patterning of the atrioventricular canal myocardium causes accessory pathway formation in mice
}

\author{
Wim T.J. Aanhaanen, Bastiaan J.D. Boukens, Aleksander Sizarov, Vincent Wakker, \\ Corrie de Gier-de Vries, Antoni C. van Ginneken, Antoon F.M. Moorman, \\ Ruben Coronel, and Vincent M. Christoffels
}

Heart Failure Research Center, Academic Medical Center, University of Amsterdam, Amsterdam, The Netherlands.

\begin{abstract}
Ventricular preexcitation, a feature of Wolff-Parkinson-White syndrome, is caused by accessory myocardial pathways that bypass the annulus fibrosus. This condition increases the risk of atrioventricular tachycardia and, in the presence of atrial fibrillation, sudden death. The developmental mechanisms underlying accessory pathway formation are poorly understood but are thought to primarily involve malformation of the annulus fibrosus. Before birth, slowly conducting atrioventricular myocardium causes a functional atrioventricular activation delay in the absence of the annulus fibrosus. This myocardium remains present after birth, suggesting that the disturbed development of the atrioventricular canal myocardium may mediate the formation of rapidly conducting accessory pathways. Here we show that myocardium-specific inactivation of T-box 2 $(T b x 2)$, a transcription factor essential for atrioventricular canal patterning, leads to the formation of fastconducting accessory pathways, malformation of the annulus fibrosus, and ventricular preexcitation in mice. The accessory pathways ectopically express proteins required for fast conduction (connexin-40 [Cx40], $\mathrm{Cx} 43$, and sodium channel, voltage-gated, type $V, \alpha[\operatorname{Scn} 5 a]$ ). Additional inactivation of $\mathrm{Cx} 30.2$, a subunit for gap junctions with low conductance expressed in the atrioventricular canal and unaffected by the loss of $T b x 2$, did not affect the functionality of the accessory pathways. Our results suggest that malformation of the annulus fibrosus and preexcitation arise from the disturbed development of the atrioventricular myocardium.
\end{abstract}

\section{Introduction}

In the heart, the atrial and ventricular muscle masses are electrically insulated from each other by the annulus fibrosus. Normally, the only muscular connection that crosses this insulation is formed by the atrioventricular (AV) node and AV bundle. In the general population, 1-3 in 1,000 individuals have accessory myocardial pathways that bypass the insulation, known as bundles of Kent $(1,2)$. These accessory connections may lead to preexcitation of the ventricle, circus movement tachycardia, and even life-threatening ventricular fibrillation in the presence of atrial fibrillation, as seen in Wolff-Parkinson-White syndrome patients (3-5). The mechanism by which these accessory myocardial connections develop and the molecular properties of these connections are largely unknown.

Accessory myocardial connections that can lead to preexcitation are commonly thought to result from malformation of the annulus fibrosus (6-9). However, during development, the AV canal myocardium causes an adequate AV delay to allow synchronized alternating contraction of the atria and ventricles (10) in the absence of an annulus fibrosus. Remnant strands of this AV myocardium, which disappear when the annulus fibrosus is fully formed $(6,11)$, have still been observed in normal hearts around birth and after birth. Usually, these strands do not lead to preexcitation, indicating they maintain slow conduction properties of the $\mathrm{AV}$ myocardium. Furthermore, in the adult heart, after formation of the annulus fibrosus has been completed, slow-conducting AV

Authorship note: Wim T.J. Aanhaanen and Bastiaan J.D. Boukens contributed equally to this work.

Conflict of interest: The authors have declared that no conflict of interest exists. Citation for this article: J Clin Invest. 2011;121(2):534-544. doi:10.1172/JCI44350. canal-type myocardium remains present around the orifices of the mitral and tricuspid valve (12-14). Together, these data suggest that AV canal myocardium plays a central role in the AV delay and that defects in AV canal myocardium could underlie formation of functional accessory pathways.

The AV canal myocardium is specified early in cardiac development. Bone morphogenetic protein $2(\mathrm{Bmp} 2)$ is expressed in the $\mathrm{AV}$ canal myocardium progenitors in the early heart tube, in which it stimulates the expression of T-box 2 (Tbx2) (15), a T-box factor required for the development of the AV canal (16-18). Repressors Tbx3 and Msx2, Notch signaling, and Hey transcription factors further establish the AV canal phenotype (19-22). Other factors involved in formation and regulation of gene expression of the AV canal and $\mathrm{AV}$ node include the more broadly expressed transcription factors Nkx2.5, Gata4, and Tbx5, which interact or compete with the localized repressors $(16,23-27)$. To explore the possible role of the $\mathrm{AV}$ canal myocardium in the formation of accessory connections, we studied the morphology and function of mice in which $T b \times 2$ was specifically inactivated in selected tissues. Our results indicate that defective patterning and gene regulation within the AV canal myocardium may lead to malformation of the annulus fibrosus, formation of accessory AV connections, and ventricular preexcitation.

\section{Results}

Tbx2 deficiency does not affect the $A V$ conduction axis but causes formation of a myocardial connection in the left AV junction. Heterozygotes containing the Tbx $2^{\text {Cre }}$ allele on an FVB/ $\mathrm{N}$ background were viable, fertile, and displayed no obvious phenotypic abnormalities. Tbx $2^{\mathrm{Cre}} / \mathrm{Tb} \times 2^{\mathrm{Cre}}$ mutants (Tbx2 $2^{-/-}$mutants) developed cleft palate and were not recovered after birth (14). Tbx2-- fetuses collected at E14.5 and E17.5 from 
A
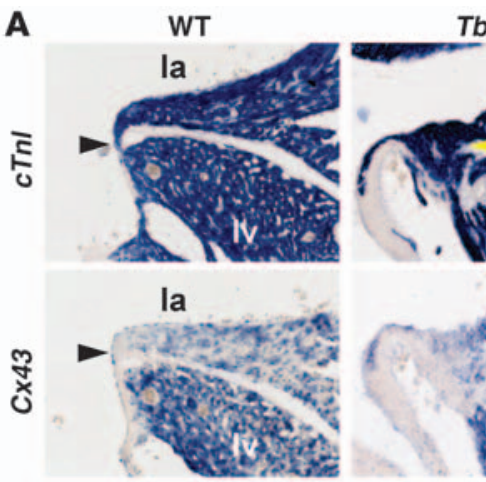

$T b \times 2^{-1}$

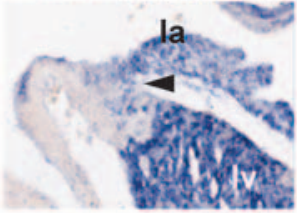

Ia

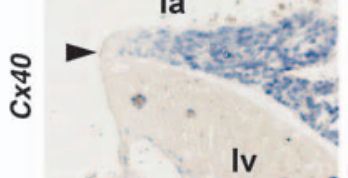

Iv

E17.5

c
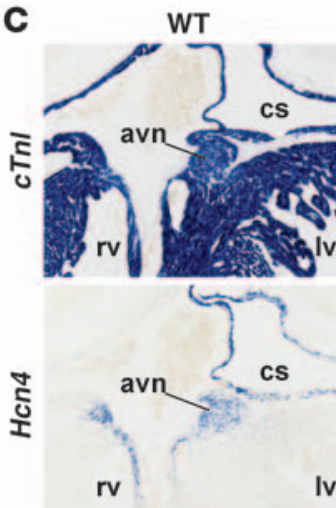

Iv

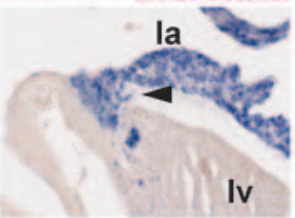

E17.5
B

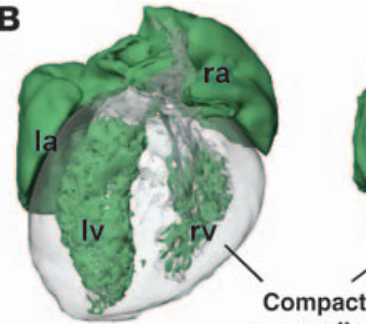
myocardium
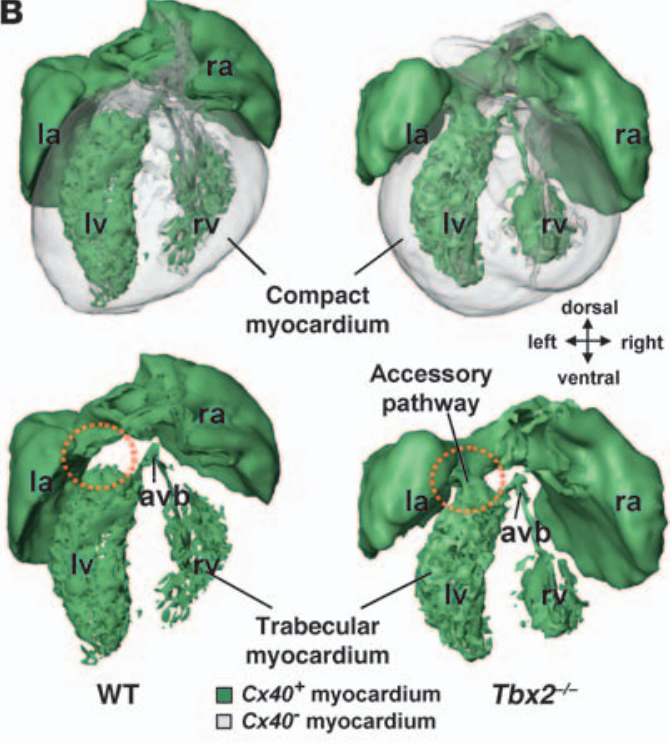

D

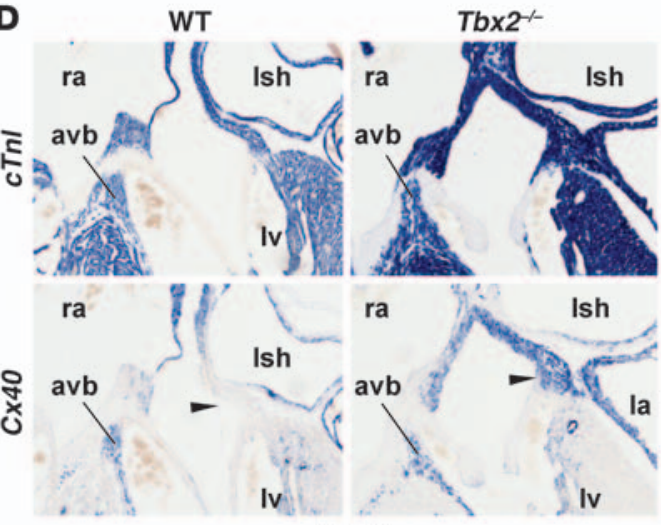

E17.5

\section{Figure 1}

In the left side of the AV canal of $T b x 2^{-/-}$fetuses, working myocardial genes are ectopically expressed and connect the left atrium with the left ventricle, while the AV node and AV bundle are unaffected. (A, C, and D) In situ hybridization analyses of serial sections wild-type and $T b \times 2^{-/-}$fetuses at E17.5. (A) In wild-type fetuses, the left AV canal myocardium (arrowheads) does not express $C \times 40$ and $C \times 43$. Tbx2 $2^{-/-}$fetuses ectopically expressed $\mathrm{Cx} 40$ and $\mathrm{C} \times 43$ in the left AV canal (arrowheads). Furthermore, the AV canal in $T b x 2^{-1-}$ fetuses was broader. (B) 3D reconstructions of the heart of wild-type and $T b \times 2^{-/}$fetuses at E17.5. Green represents $C \times 40$-positive myocardium, and gray represents $C \times 40$-negative myo-

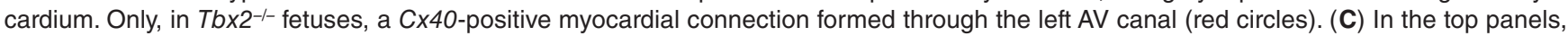
$c T n /$ reveals the myocardium. The bottom panels show the AV node based on Hcn4 expression and location. The AV node is not affected in $T b \times 2^{-/-}$fetuses. (D) In the top panels, $c T n l$ reveals the myocardium. The bottom panels show the AV bundle based on $C x 40$ expression and location. The AV bundle is not affected in $T b \times 2^{-/}$fetuses. la, left atrium; ra, right atrium; avb, AV bundle; avn, AV node; cs, coronary sinus; Ish, left sinus horn. Original magnification, $\times 10(\mathbf{A}) ; \times 5(\mathbf{C}$ and $\mathbf{D})$.

heterozygous intercross matings were present at lower numbers than would be expected on the basis of Mendelian inheritance (Supplemental Figure 1C; supplemental material available online with this

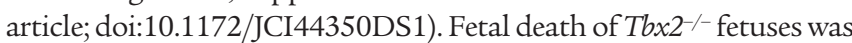
less severe than that found previously for another Tbx2-null allele on the mixed C57BL/6/129/ICR background (17). Surviving E14.5 and E17.5 fetuses were of normal size and were used for further analysis. We assessed whether chamber-specific genes involved in conduction of the electrical impulse were ectopically expressed in the AV canal

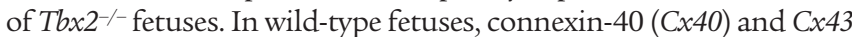
were not expressed in the AV canal myocardium at E14.5 and E17.5. In contrast, $C x 40$ and $C x 43$ were ectopically expressed in the left side of the AV canal myocardium in all $T b \times 2^{-/-}$littermates $(n=18$; Figure $1 \mathrm{~A}$ and Supplemental Figure 1A). The right AV canal myocardium was not affected in mutants (Supplemental Figure 1B). The right side of the AV canal is presumably under control of $T b \times 3$ to a larger extent compared with the left side (18). The redundant function of Tbx3 is illustrated by the ectopic expression of $C \times 40$ in the epicardial side of the left AV canal, complementary to that of $T b x 3$ at the endocardial side (Supplemental Figure 1A). Sodium channel, voltage-gated, type $\mathrm{V}, \alpha(\operatorname{Scn} 5 a)$, encoding the major cardiac sodium channel (Nav1.5) that is required for fast conduction, was expressed in the AV junction of $T b \times 2^{-/-}$but not in wild-type animals. Heterozygous $T b \times 2$ mutants were not different from wild-type animals (data not shown). 
A
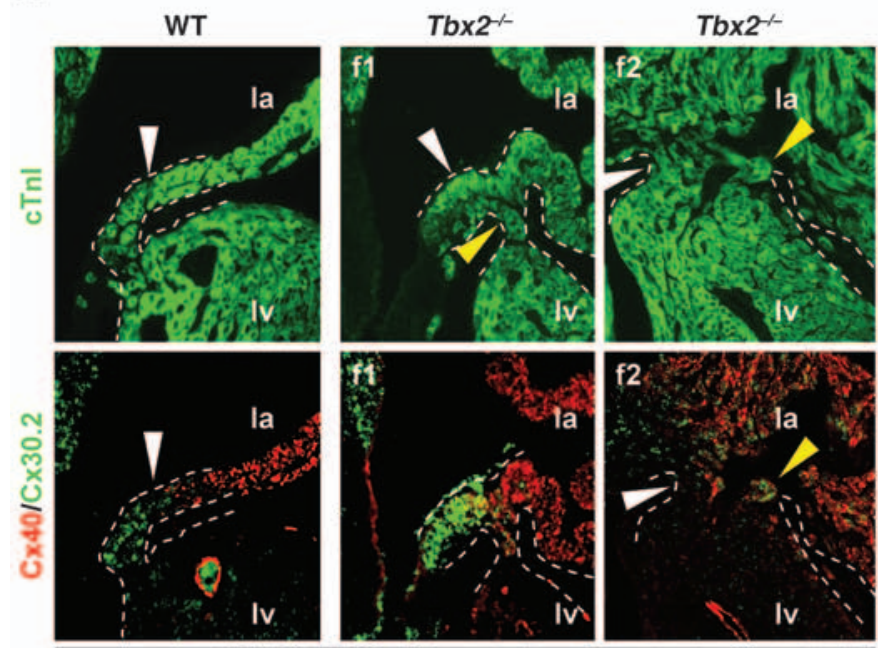

E14.5

\section{C}
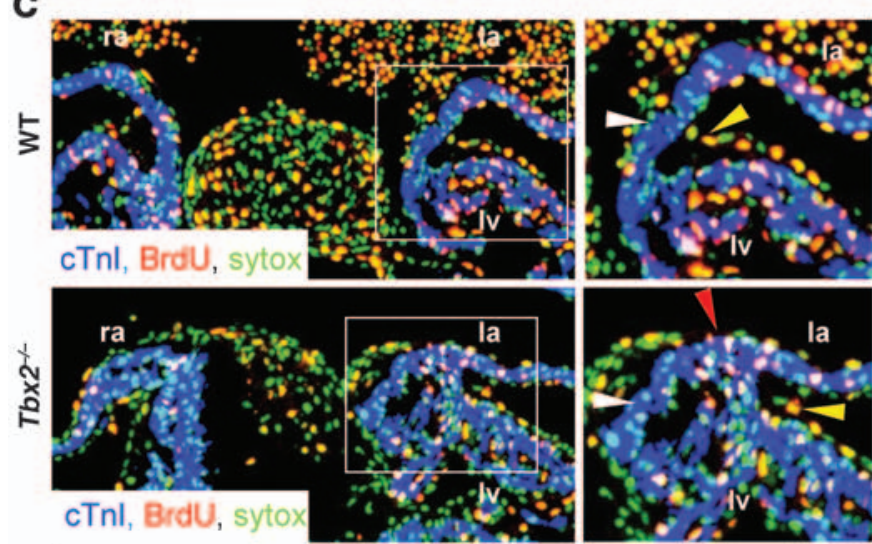

E11.5
B

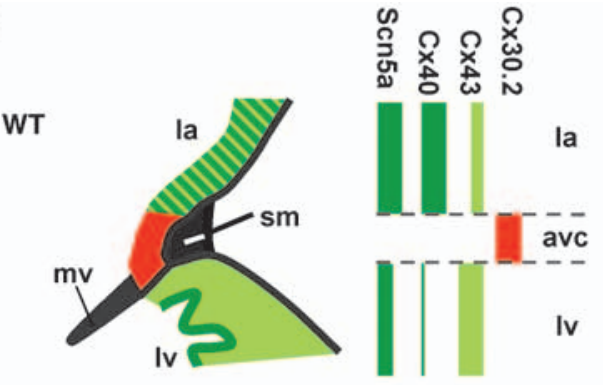

$\operatorname{Tb} \times 2^{-1-}$

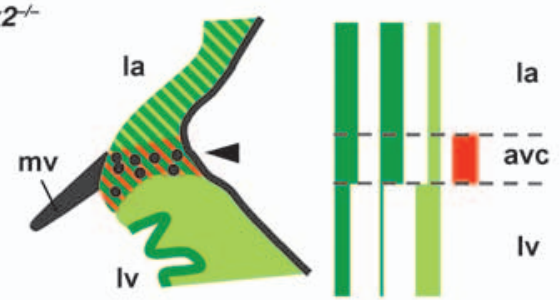

D

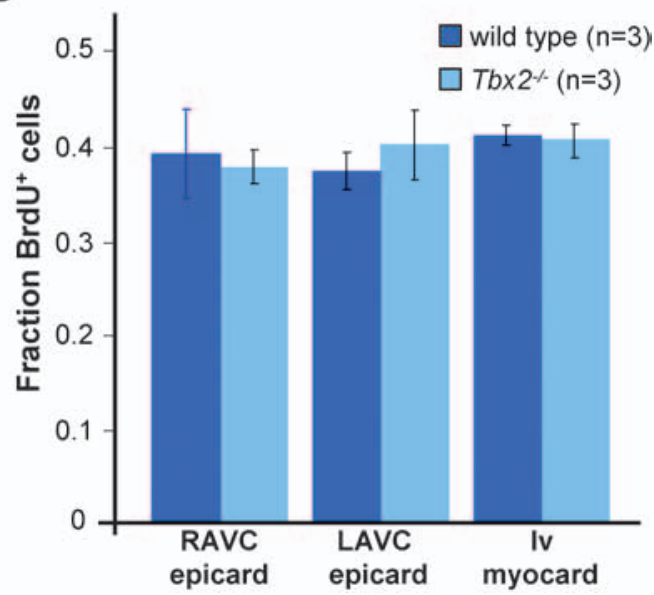

Figure 2

In the left side of AV canal of $T b \times 2^{--}$fetuses working myocardial proteins are ectopically expressed. The proliferation rate in the epicardium is not different between wild-type and $T b x 2^{-1-}$ fetuses. (A) Immunohistochemical analyses of serial section of E14.5 wild-type fetuses and 2

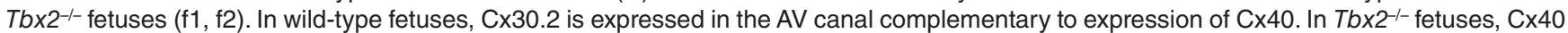
is expressed ectopically in the AV canal, and Cx30.2 is still expressed in the AV canal myocardium. Notice the variable size and morphology of the aberrant myocardial connection. The white and yellow arrowheads point to the AV canal myocardium. The dashed lines mark the myocardium that connects the left atrium and the left ventricle. (B) Schematic representation of the expression profiles of connexins in the left AV canal myocardium in wild-type and Tbx2-1- fetuses. Note that Cx40 expression withdraws from the compact myocardium; however, Cx43 remains present. Dots represent nonmyocardial cells of the malformed annulus fibrosus. (C) Immunohistochemical analyses of BrdU incorporation in epicardial

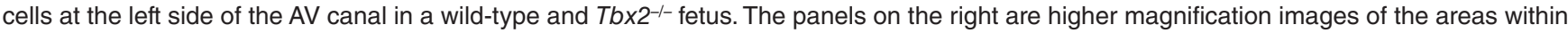
the white squares in the panels on the left. The white arrowhead points to the AV myocardium. The red arrowhead points to BrdU+ myocardial cells in the AV myocardium. The yellow arrowhead points to a BrdU+ epicardial cell. (D) A bar graph representing the proliferation rate, based on BrdU incorporation in the myocardium (myocard) of the left ventricle and in the epicardium (epicard) at the right and left side of the AV canal. avc, AV canal; mv, mitral valve; sm, sulcus mesenchyme; LAVC, left AV canal; RAVC, right AV canal. Original magnification, $\times 10$ (A and C).

In the Tbx2/- fetus, the compact AV node (hyperpolarizationactivated cyclic nucleotide-gated channel $4[\mathrm{Hcn} 4]$ positive) and AV bundle (Cx40 positive) were not affected (Figure $1, \mathrm{C}$ and $\mathrm{D})$ and were not in contact with the aberrantly formed $C x 40$-positive (and Cx43-positive) myocardial connection. 3D reconstructions

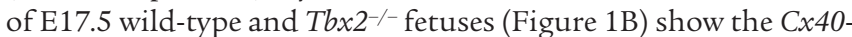
positive pathway in the $T b \times 2^{-/-}$fetus that is not connected to the AV conduction axis (Figure 1B).
To assess whether the patterns of Tbx 2 and $\mathrm{Cx} 40$ are conserved in humans, we analyzed the expression of these proteins in a human fetus at Carnegie stage 14 (comparable to mouse E11.5). As in mice, TBX2 and TBX3 were expressed in the AV canal myocardium, whereas CX40 was strictly absent from the AV canal myocardium but expressed in the atrial and ventricular myocardium (Supplemental Figure 2).

Next, we investigated the formation of the annulus fibrosus in Tbx2-/- embryos. In wild-type embryos at E14.5, when annulus 


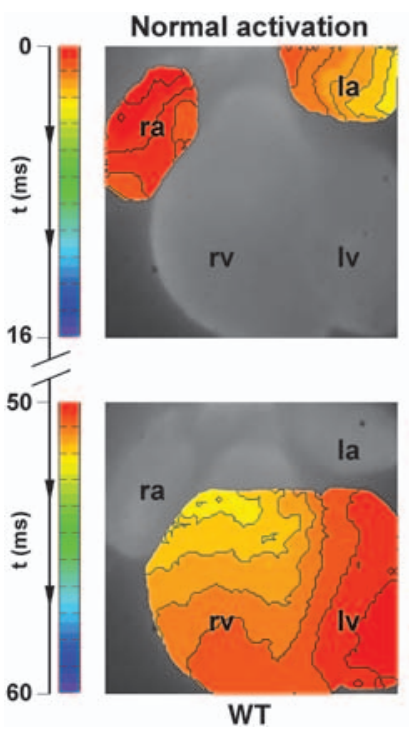

WT

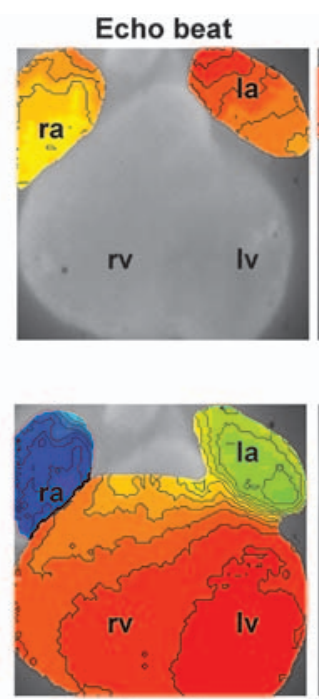

Tbx2--
Preexcitation
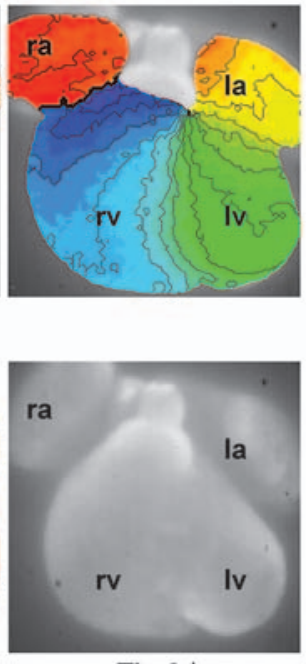

Tbx $2^{-1-}$

\section{Figure 3}

Typical example of an activation pattern in a wild-type and $\mathrm{Tb}_{\mathrm{b}} \mathrm{2}^{-/-}$hearts at E14.5. In the wild-type heart, activation starts in the atria, and after a delay of $50 \mathrm{~ms}$ the ventricles are activated within $3 \mathrm{~ms}$ after the first moment of activation of the apex of the left ventricle. In the middle panel, an activation pattern of a $\mathrm{Tb}_{\mathrm{b}} \mathrm{2}^{-/-}$heart is shown. The activation starts in the atria, and after a normal AV delay, the ventricles are activated from apex to base, after which the atria are activated for the second time via the left side. The right panel shows an example of ventricular preexcitation in a $\mathrm{Tb}_{\mathrm{C}} \mathrm{2}^{-/-}$heart. The activation starts in the atria, after which the base of the left ventricle is activated with an AV delay of $8 \mathrm{~ms}$. Complete activation of both the left and right ventricle is within $15 \mathrm{~ms}$. Original magnification, $\times 5$. fibrosus formation is in progress, a narrow myocardial AV junction connected the atria with the ventricles. At E17.5, the atria and ventricles were almost completely separated by the annulus fibrosus, although many small myocardial connections were still observed. However, in Tbx2 $2^{-/-}$animals at E17.5, a myocardial connection in the left AV junction was formed. The size and morphology of the connection varied between animals (Figure 2, A and B). Nonmyocardial cells intermingled with the persisting myocardial connection but did not form a complete separation. The right AV junction developed normally.

In Tbx $2^{-/-}$animals, the sulcus mesenchyme is normally formed at the right side of the AV canal, while it is not formed at the left side. The proliferation rate of the epicardial sulcus was found to be similar between wild-type $(0.36 \pm 0.019$ fraction of epicardial cells positive for BrdU) and $\mathrm{Tb} \times 2^{-/-}$animals $(0.38 \pm 0.036$ fraction of epicardial cells positive for BrdU) (Figure 2, C and D). Previously, we established an increased proliferation rate in the left $\mathrm{AV}$ canal of Tbx2-/- animals at E9.5 (18). At E11.5, the epicardial side of the left AV canal myocardium of the Tbx2-/- animals had an increased proliferation profile compared with that of the wild-type animals (Figure 2C). Neither wild-type $(n=3)$ nor Tbx $2^{-/-}$embryos $(n=3)$ showed apoptosis in the right $\mathrm{AV}$ junction myocardium and epicardium at E11.5 (data not shown). These data suggest that the annulus fibrosus is malformed due to altered migration or dysmorphogenesis of the sulcus mesenchyme.

Preexcitation of the ventricles and retrograde activation of the atria in Tbx $2^{-/-}$mice. In all E14.5 wild-type $(n=5)$ and Tbx $2^{+/-}$fetuses $(n=6)$, the left ventricle was activated from apex to base within $2 \mathrm{~ms}$, after an AV delay of $67 \pm 18 \mathrm{~ms}$ during sinus rhythm. However, we observed a functional accessory pathway in 6 out of $14 \mathrm{~Tb} \times 2^{-/-}$fetuses. Five out of fourteen $T b \times 2^{-1-}$ fetuses showed retrograde activation of the atria after a normal AV delay. In 1 out of $14 \mathrm{~Tb} \times 2^{-/-}$fetuses, we observed that the ventricular myocardium was completely activated via the accessory pathway during sinus rhythm, after an AV delay of only $8 \mathrm{~ms}$ (Figure 3 and Supplemental Videos 1-3). The location of the earliest ventricular activation coincided with the location of the accessory pathway, as shown in the $3 \mathrm{D}$ reconstruction (Figure 1B). The ventricular activation pattern and total excitation time of the atria and ventricles (Figure 3 ) indicated that the AV conduction axis (AV node and bundle) was not involved in activation of the ventricular myocardium in this heart. Nevertheless, the AV conduction axis appeared to be intact, because this heart also showed periods of normal AV conduction in which the ventricular myocardium was activated from the apex to base, with an AV delay of $51 \mathrm{~ms}$.

At E17.5, the average AV conduction delay in wild-type $(n=5)$ and heterozygous $(n=6)$ mice was not significantly different $(72 \pm 1.3 \mathrm{~ms}$ and $56.1 \pm 4.7 \mathrm{~ms}$, respectively). In 6 out of 13 of the $T b \times 2^{-/-}$fetuses, we found a functional, conducting accessory pathway (Table 1). One of these fetuses showed complete activation of the ventricle via the accessory pathway during sinus rhythm, with an AV delay of $8.5 \mathrm{~ms}$, and 5 fetuses showed normal activation of the ventricles with subsequently retrograde activation of the left atrium. During ventricular stimulation, the ventricle to atrium conduction delay was $16.5 \pm 5.5 \mathrm{~ms}$ in Tb $x 2^{-/-}$fetuses and $92 \pm 48 \mathrm{~ms}$ in wild-type fetuses $(P<0.05)$. We tested whether delaying AV nodal conduction would reveal concealed pathways. However, administration of adenosine did result in AV block, suggesting absence of functional accessory pathway $(n=3)$.

The AV canal-specific gene program, including Cx30.2 expression, is not affected in Tbx $2^{-/-}$fetuses. Although all the Tbx $2^{-/-}$fetuses examined formed left-sided AV connections expressing working myocardial genes and had a malformed annulus fibrosus, only a subpopulation of the $T b \times 2^{-/-}$fetuses showed a conducting accessory pathway. A possible explanation for the discrepancy is that intrinsic factors in the myocardium that are independent of Tbx2 influence conduction in the $\mathrm{AV}$ junction. $\mathrm{Cx} 30.2$ is a connexin subunit with low conductance, which is expressed in the AV node where it decelerates conduction (28), and depends on Gata factors and Tbx5 for its expression in the AV canal (24). Coimmunostaining for $\mathrm{Cx} 40$ and $\mathrm{Cx} 30.2$ revealed that $\mathrm{Cx} 30.2$ was expressed in the AV canal myocardium of the fetal heart complementary to $\mathrm{Cx} 40$ (Figure 2A). In Tbx2-/- hearts, Cx30.2 remained expressed in the AV junction that now ectopically coexpressed Cx40. Expression of AV canal-specific genes, $H c n 4$, calcium channel, voltage-dependent, $\alpha 2 / \delta$ subunit 2 (Cacna2d2), calcium channel, voltage-dependent, T type, $\alpha 1 \mathrm{G}$ subunit (Cacna1g) (Cav3.1), and inhibitor of DNA binding 2 (Id2), was also maintained in the malformed left AV canal of $T b \times 2^{-1-}$ fetuses (Figure 4). Our findings indicate that regulation of these AV canal genes, including $\mathrm{Cx} 30.2$, is independent of Tbx 2 . 
Table 1

Presence of a functional accessory pathway in mice

\begin{tabular}{|c|c|c|c|c|}
\hline & & E14.5 & E17.5 & Adult \\
\hline FVB/N & 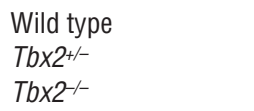 & $\begin{array}{l}0(n=6) \\
0(n=8) \\
1(n=6)\end{array}$ & $\begin{array}{l}0(n=5) \\
0(n=6) \\
6(n=13)\end{array}$ & $\begin{array}{c}0(n=5) \\
- \\
-\end{array}$ \\
\hline Mixed FVB/N;C57BL/6 & $\begin{array}{l}\text { Tbx } \times 2^{-/-C} \times 30.2^{+/+} \\
T b \times 2^{-/-C} \times 30.2^{+/ L a c Z} \\
T b \times 2^{-1-C} \times 30.2^{L a c z / L a c z}\end{array}$ & $\begin{array}{l}5(n=8) \\
6(n=9) \\
7(n=11)\end{array}$ & $\begin{array}{l}- \\
- \\
-\end{array}$ & $\begin{array}{l}- \\
- \\
-\end{array}$ \\
\hline FVB/N & $\begin{array}{l}\text { Myh6-CreTbx2+ffl } \\
\text { Myh6-CreTbx2 }\end{array}$ & - & - & $\begin{array}{l}0(n=5) \\
7(n=7)\end{array}$ \\
\hline
\end{tabular}

enchyme of the AV cushions $(32,33)$. However, lineage analyses revealed that the annulus fibrosus did not receive the contributions of these cells (ref. 32 and data not shown). Wnt1-Cre labels all the neural crest, including the innervations of the heart (30). Wnt1-Cre-derived cellular contributions to the AV canal region are very limited $(30,32)$. In all 3 lines examined, the AV canal myocardium was normally patterned, and the sulcus mesenchyme, the precursor of the annulus fibrosus, was normally formed (Supplemental Figure 3). Tie2CreTb $\times 2^{f l f l}$ and Mef2c-AHF-CreTb $\times 2^{f l / f l}$

To test whether maintained $\mathrm{Cx} 30.2$ expression contributed to the AV delay in mutants, we generated double mutants for Tbx2 and $C \times 30.2$ by intercrossing $T b \times 2^{+/ C r e} C \times 30.2^{+/ L a c Z}$ transgenic mice. $\mathrm{AV}$ conduction time and activation pattern were assessed by optical mapping of fetal hearts at E14.5 $(n=11)$. The fraction of Tbx2 mutants with functional bundles was not affected by the presence or absence of $C \times 30.2$ (Table 1 ).

Myocardium-specific inactivation of Tbx2 results in accessory pathways and defective annulus fibrosus formation. Tbx2 is expressed in the AV canal myocardium and in the AV cushion mesenchyme, which is implicated in annulus fibrosus formation (29). Furthermore, Tbx2 is expressed in the neural crest, which has been associated with the formation of the conduction system (30), in the second heart field, and in the dorsal mesenchymal protrusion-derived cells that contribute to the AV septation process (31). We assessed the function of $T b \times 2$ in these different cell lineages by inactivating $T b \times 2$, specifically in endocardium and derived cushion mesenchyme, the neural crest, or the second heart field and dorsal mesenchymal protrusion-derived cells by crossing Tbx $2^{f / f l}$ mice with the Tie2CreTbx2 $2^{+/ f l}$, Wnt1-CreTb $\times 2^{+/ f l}$, or Mef2c-AHF-CreTb $\times 2^{+/ f l}$ mice. Tie2Cre recombines all endothelia, endocardium, and derived mes- mice were viable, and $\mathrm{AV}$ conduction was not altered in adult mice (data not shown). Wnt1-CreTbx $2^{f / / f l}$ mice died at birth due to cleft palate and were measured at E17.5. Also, in these mutants, AV conduction was not altered (data not shown).

Next, Tbx2 was specifically inactivated in the myocardium by crossing Tbx $2^{f l / f l}$ mice with Myb6-CreTb $x 2^{+/ f l}$ mice. At E10.5, Tbx2 protein was not found in the AV canal myocardium of Myb6CreTb $\times 2^{f l / f l}$ mutants but was still observed in the AV cushions (Supplemental Figure 4A). The left AV junction ectopically expressed $\mathrm{Cx} 40$, whereas $\mathrm{Tbx} 3$ was still expressed robustly at the luminal side of the left AV canal (Supplemental Figure 4A). The cardiac phenotype of Myb6-CreTbx $2^{f l / f l}$ mice and $T b x 2^{-/-}$mice is similar. To study annulus fibrosus formation, we assessed the patterning of the epicardial cells in the Myb6-CreTbx $2^{f l / f l}$ mice at E12.5 by examining markers that are expressed in the epicardial cells and in the epicardial derived sulcus mesenchyme, which include periostin (Postn), collagen, type III, $\alpha 1$ (Col3a1), Tbx18, and Wilms tumor 1 homolog (Wt1). In E12.5 wild-type hearts, annulus fibrosus formation was ongoing. In the AV sulcus, epicardial-derived mesenchymal cells were found that express Postn, Col3a1, and Wt1. In Myb6-CreTbx $2^{f l f l}$ fetuses, the sulcus

\section{Figure 4}

Genes typical for the AV canal and genes typical for the working myocardium are simultaneously expressed in the left side of the AV canal of $T b \times 2^{--}$fetuses. In situ hybridization analyses in sections of (A and $\mathbf{B}$ ) wild-type fetuses and

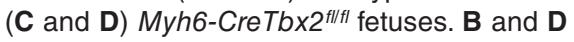
show higher magnification images of the areas within the black squares in $\mathbf{A}$ and $\mathbf{C}$, respectively. (A and $\mathbf{C}$ ) cTnl labels the myocardium. (B) In wild-type fetuses, the AV canal myocardium (black arrowheads) did not express Cx40 and Scn5a (also known as Nav1.5), genes associated with fast conduction. The AV canal myocardium did express typical AV canal genes associated with slow conduction (Cacna1g and Cacna2d2), automaticity (Hcn4), and AV conduction system maturation (Id2). (D) In $\mathrm{Tb}^{2} 2^{-1-}$ fetuses, Cx40 and Scn5a are ectopically expressed in the left AV canal myocardium. The AV canal-specific genes are still expressed and even found in the left ventricular wall in some cases (red arrowheads). Original magnification, $\times 5(\mathbf{A}$ and $\mathbf{C}) ; \times 10(\mathbf{B}$ and $\mathbf{D})$.

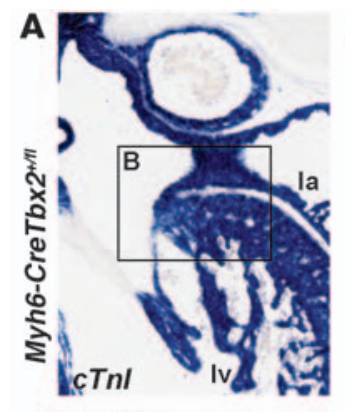

B
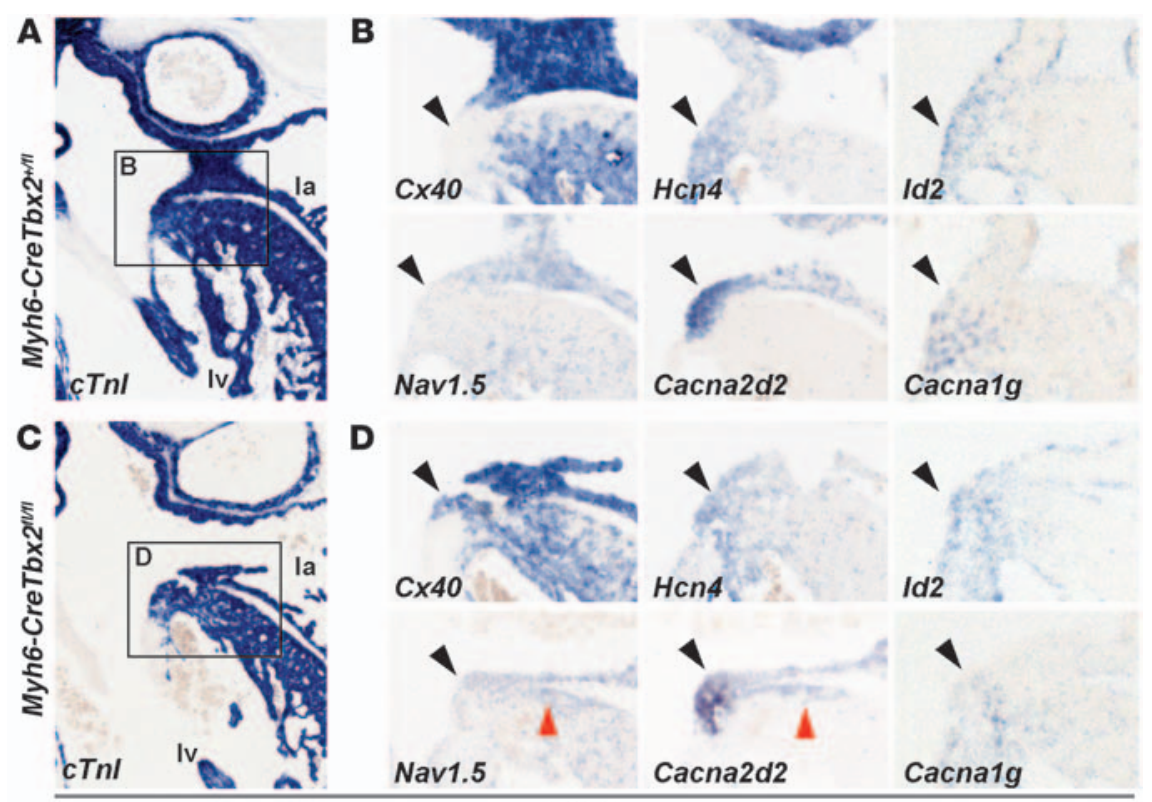

D
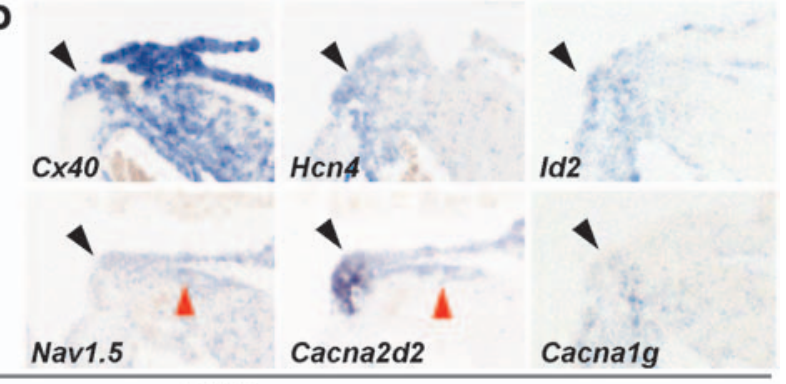

E14.5 
A

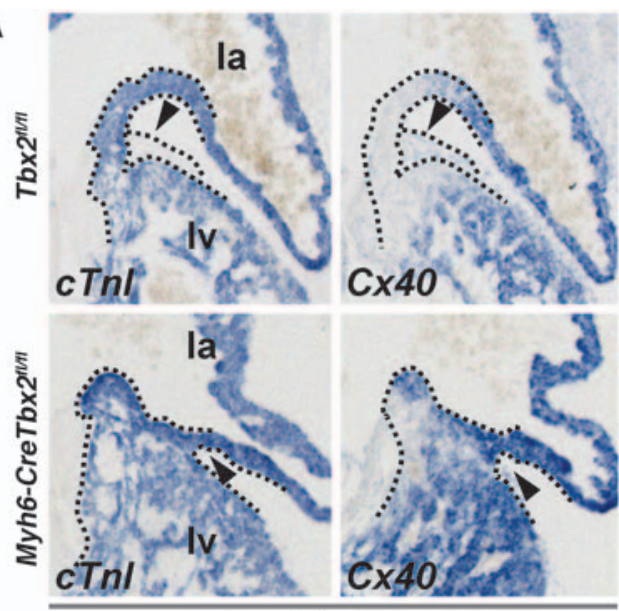

E12.5

B

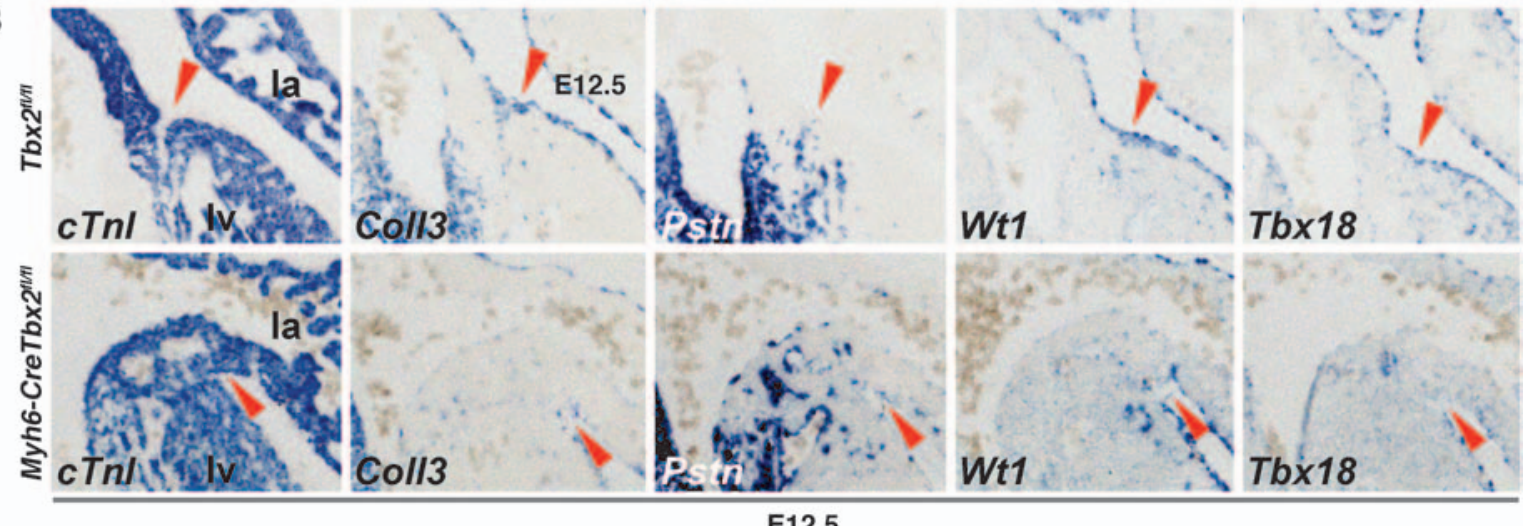

Figure 5

Absence of Tbx2 in the AV canal myocardium leads to absence of epicardial derived mesenchyme and abnormal epicardial patterning. (A) In situ hybridization analyses of E12.5 Tbx2 $2^{f / f t}$ and Myh6-CreTbx2 ${ }^{f / / f l}$ embryos. When $T b x 2$ is inactivated within the myocardium $C \times 40$ is ectopically expressed in the shortened and broadened AV canal myocardium. Furthermore, the accumulation of epicardial derived mesenchyme in the left AV sulcus is lost (black arrowheads). Dashed lines depict the contours of the myocardium (cTnl+) and epicardial sulcus (cTnl-) in the AV region. (B) Tbx2 in the AV canal myocardium is required for correct patterning of the epicardium and the accumulation of epicardial derived mesenchyme

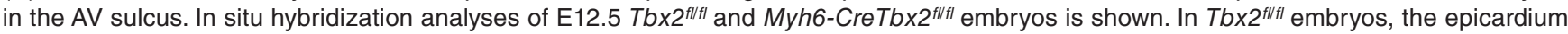
derived mesenchyme accumulates specifically in the AV sulcus and invaginates in between the atria and ventricles. Co/3a1 (Col/3), Tbx18, and Wt1 are expressed in the epicardium and epicardial derived mesenchyme that also expressed Postn (Pstn). In the Myh6-CreTbx2 ${ }^{\text {t/lfl} ~ e m b r y o s, ~}$ the epicardial derived mesenchyme fails to accumulate in the AV sulcus, and the examined genes are aberrantly expressed (red arrowheads). Original magnification, $\times 10$ (A and $\mathbf{B})$.

mesenchyme at the left AV junction was not formed (Figure 5A). Furthermore, Col3a1 and Wt1 expression was decreased in the $\mathrm{AV}$ sulcus and $T b \times 18$ expression appeared diminished (Figure $5 \mathrm{~B})$. This indicates that Tbx2 function in the AV myocardium influences the formation of AV sulcus mesenchyme and that the formation of the annulus fibrosus is not properly initiated.

Myb6-CreTbx $2^{f l / f l}$ animals survived after birth at lower frequency than expected on the basis of Mendelian inheritance $(P<0.05$, Table 1$)$. This could be due to variations in the degree of recombination of $T b x 2$ or in viability. However, recombination by Myb6-Cre in the AV canal is complete by E10.5 (32), and a fraction of the $T b \times 2^{-/-}$mice also survived until late fetal stages, suggesting that the survival of the Myb6-CreTbx $2^{f l f l}$ animals can be attributed to variability in phenotype. All adult Myb6-CreTbx $2^{f / f l}$ animals studied $(n=7)$ had persisting myocardial strands that connected the left atrium with the left ventricle and that expressed $\mathrm{Cx} 40$ and $\mathrm{Cx} 43$ (Figure 6J). The myocardial connections varied in size from small strands to a relatively thick connection. More importantly, the accessory connection were always found at the left and caudal side of the AV junction and did not affect the compact AV node nor AV bundle (Figure 6, A-G). In both wild-type and Myb6-CreTbx $2^{f l / f l}$ mice, $\mathrm{Cx} 30.2$ expression was no longer detectable in the AV junction but was detectable in the AV node (Supplemental Figure 4B).

ECG recordings revealed that 4 out of 8 mice with myocardium-specific inactivation of Tbx2 had a normal PR interval $(34.6 \pm 4.0 \mathrm{~ms}$ ) (Table 2$)$. The other 4 mice showed a severely shortened PR interval, with a broadened QRS complex and initial slurring consistent with preexcitation (Figure $6 \mathrm{H}$ ). The total activation time of the atria and ventricles with preexcitation is less than the normal AV delay. Therefore, the AV node and AV bundle complex are not used to activate (part of) the ventricle. 
Hence, these QRS complexes are not a representation of a fusion of normal activation and preexcitation via the accessory bundle. We therefore prefer not to describe this initial deflection as a delta wave.

Optical mapping of adult Myb6-CreTbx $2^{f l / f l}$ hearts in a Langendorff setup showed that the ventricular myocardium was completely activated during preexcitation, without the involvement of the AV nodal conduction axis (Figure 6I). Furthermore, all Myb6$\mathrm{CreTb} \times 2^{f l / f l}$ adult hearts that were investigated showed a shorter AV delay than that in wild-type hearts $(13 \pm 2 \mathrm{~ms}$ vs. $52.4 \pm 8.9 \mathrm{~ms})$. In some hearts, atrial echo beats could be induced after premature stimulation (Supplemental Figure 5). Arrhythmias could not be induced in any of the adult Myb6-CreTbx $2^{f / f l}$ mice. Administration of sodium channel blocker ajmaline converted ventricular preexcitation into normal AV conduction $(n=3)$.

\section{Discussion}

In this study we show that global and myocardium-specific inactivation of Tbx2 causes formation of accessory AV bundles and preexcitation of the ventricles. The importance of our findings is that erroneous patterning in part of the embryonic AV canal myocardium can be the primary event in the formation of accessory pathways, leading to preexcitation and to malformation of the insulating annulus fibrosus.

The cardiac Tbx2 mutant provides a paradigm for the developmental mechanisms that can lead to accessory pathways. Both Tbx2 mutant mice and patients with preexcitation have myocardial accessory pathways that express $\mathrm{Cx} 43$ (34). Therefore, we propose that the formation of a fast-conducting muscular connection between the atrium and the ventricle that bypasses the $A V$ conduction axis in the Tbx2 mutants and in patients with preexcitation can share a similar underlying developmental mechanism. However, the phenotypic outcome of these pathways differs between mice and human.

First, there is an essential difference between preexcitation in patients and preexcitation in mouse models. In contrast to patients with preexcitation, in which a delta wave is often seen, mouse models with preexcitation show activation patterns that indicate complete activation of the ventricle without involvement of the AV conduction system (35-40). In mice the AV delay is relatively long compared with the total activation time of the ventricles. Therefore, a fusion complex, as seen in humans, is less likely to occur, especially when conduction via an accessory pathway is fast. Indeed, in our model, the sum of the activation delay in the accessory pathway and the total ventricular activation time was shorter than the normal AV delay. These data indicate that in mice the ventricle is completely activated through the accessory pathways.

Second, in mice the AV node has a relatively long refractory period compared with the conduction time along the reentrant circuit. Therefore, it is difficult to induce AV nodal reentrant tachycardia in mice. However, we were able to induce an atrial echo beat via administration of a sodium channel blocker (Ajmaline) (Supplemental Figure 5).

Third, the pathways in Tbx2 mutants were variable in size and always located at the left-posterior (caudal) side of the AV junction. In patients with preexcitation, the pathways are often relatively smaller and can be located at any position in the AV junction, although there is a preference for the left and posterior location as well (41). In addition, the accessory bundles in humans are at the epicardial side of the annulus fibrosus.

Taken together, although the physiological outcome differs between patients with preexcitation and Tbx2 mutant mice, we conclude that the underlying developmental mechanisms of accessory pathway formation are similar, making the Tbx2 mutant model a valuable tool to study and understand these molecular mechanisms of accessory bundle formation.

Although an accessory connection was formed in all Tbx2-/fetuses that expressed Cx40, Cx43, and Scn5a, not all Tbx2-/- fetuses had a conducting accessory pathway (Table 1). We hypothesized that other AV-specific genes may have modulated accessory pathway formation. However, the presence or absence of $\mathrm{Cx} 30.2 \mathrm{did}$ not influence the percentage of mutant fetuses with functional accessory pathways (Table 1). Alternatively, the size and fiber direction of the accessory bundle may vary between mutants. This can affect conduction through these accessory pathway through a mechanism known as current-to-load mismatch, in which small myocardial strands are not able to activate a large myocardial area (42). Indeed, upon blocking the sodium current, we enhanced the intrinsic current-to-load mismatch and were able to convert preexcitation into retrograde atrial activation or even normal AV conduction in the adult Myb6-CreTbx $2^{f l / f l}$ mice. This indicates that variations in the occurrence of current-to-load mismatch determine whether an accessory pathway causes preexcitation or not.

Developmental mechanisms of AV accessory pathway formation. Several mechanisms for accessory pathway formation have been put forward and discussed previously (43): (a) malformation of the annulus fibrosis (6-9), (b) acquired during fetal or postnatal life (29), and (c) misregulation of AV canal myocardium. Our study supports the latter explanation for the formation of functional accessory pathways.

During development, the AV canal provides an adequate AV delay to allow synchronized alternating contraction of the atria and ventricles (10). Remnant strands of this myocardium have still been observed in normal hearts around and after birth (11). Furthermore, in the adult heart, after formation of the annulus fibrosus has been completed, slow-conducting AV canal-type myocardium remains present around the orifices of the mitral and tricuspid valve (12-14). Defects in the annulus fibrosus alone may therefore not automatically lead to preexcitation. Our study helps to reconcile these observations. Myocardium-specific inactivation of Tbx2 caused erroneous gene expression and morphogenesis of part of the embryonic AV canal. As a result, AV myocardium was malformed and acquired fast-conducting properties, and annulus fibrosus formation was affected, which led to preexcitation. The myocardial pathways were seen to develop mainly at the epicardial side, whereas the medial/endocardial side was largely unaffected, likely due to the redundant function of Tbx3, a functional homolog of Tbx2 (Supplemental Figure 1A) (18).

The malformation of the annulus fibrosus can be caused by disturbed epicardial ingression (29) at the level of the AV sulcus, due to dysmorphogenesis of the AV canal myocardium in Tbx2 mutants. On the other hand, the epicardium-derived mesenchymal material, which is formed before ingression, was not formed at the left side in myocardium-specific Tbx2 mutants. Furthermore, the patterning of the epicardium was disrupted, as shown by altered expression of marker genes. These findings indicate the existence of a Tbx2-dependent signal in the AV canal myocardium that is involved in the formation of the annulus fibrosus.

Disruption of the AV canal regulatory network underlies accessory bundle formation. Our study indicates that disturbed AV canal development is linked with formation of accessory pathways and preexcitation. Several genes have been implicated in AV 

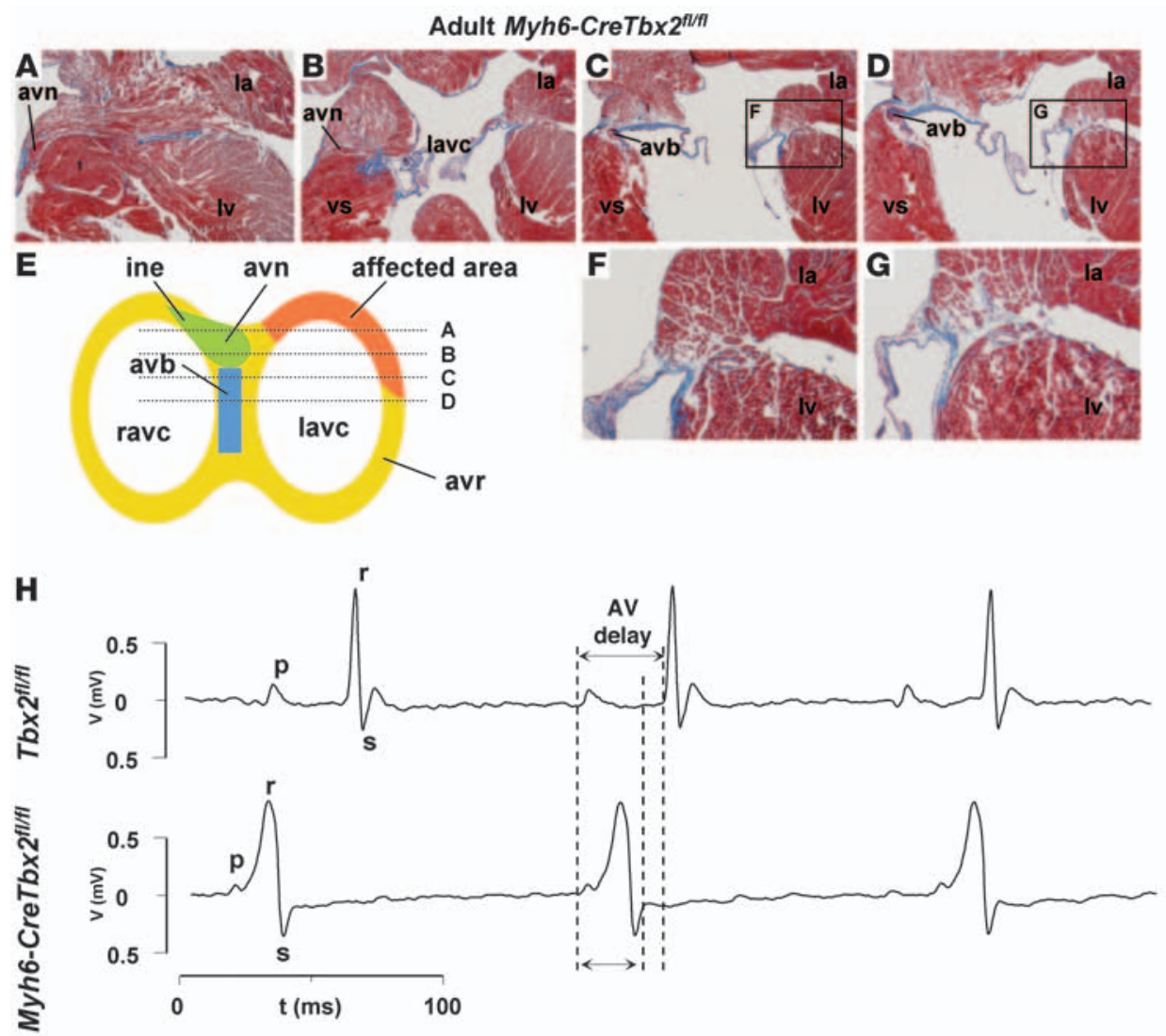
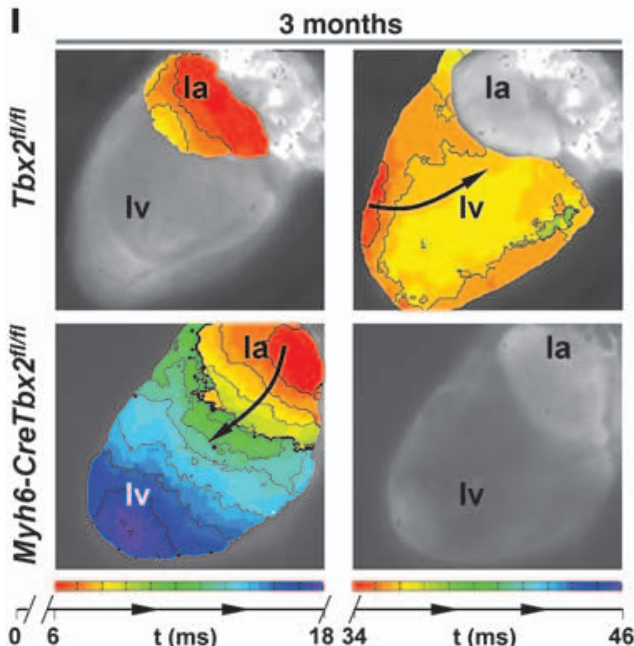

$\mathbf{J}$

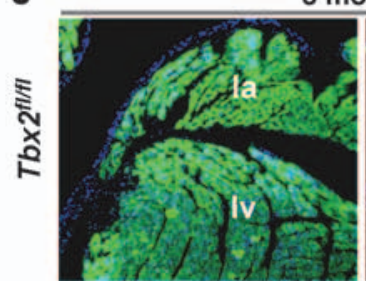

3 months

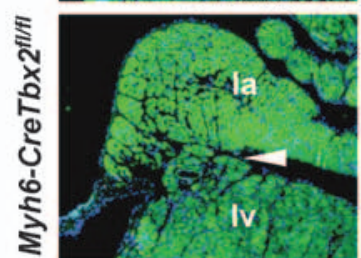

cTnI/dapi
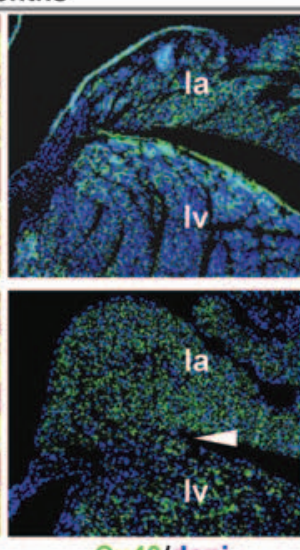

Cx43/dapi

\section{Figure 6}

Myocardial specific deletion of Tbx2 leads to formation of accessory pathways that express $C x 43$ and causes ventricular preexcitation without involvement of the AV conduction axis. (A-D) Images of sections, stained via the classical Masson-trichome protocol, of a representative adult Myh6-CreTbx2 $2^{f / f l}$ animal. The location of each section is shown in the schematic representation in E. (E) The affected area is always located at the left and caudal side of the AV junction, while the AV conduction axis remains intact. $\mathbf{F}$ and $\mathbf{G}$ show higher magnification images of the areas within the black squares in $\mathbf{C}$ and $\mathbf{D}$, respectively. $(\mathbf{H})$ The ECG shows ventricular preexcitation in a Myh6-CreTbx ${ }^{\mathrm{fl} / \mathrm{fl}}$ mouse and normal AV delay in a wild-type mouse (top). Note that the AV delay in the wild-type mouse is longer than the total activation time in the Myh6-CreTbx2 ${ }^{f / f l}$ mouse. (I) Reconstructed activation pattern of a representative wild-type mouse (top) and Myh6-CreTbx2 ${ }^{f / f l}$ adult mouse. In the wild-type mouse, after an AV delay of $34 \mathrm{~ms}$, the ventricle is activated from apex to base. In the Myh6-CreTbx2 $2^{\mathrm{flfl} l}$ mouse, the ventricle is activated from base to

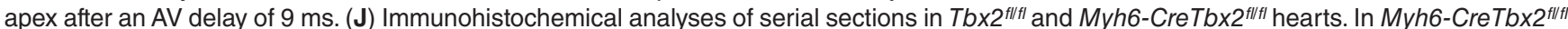
hearts, Cx43 is expressed in the accessory myocardial connection. vs, ventricular septum; avr, AV ring; ine, inferior nodal extension. Original magnification, $\times 2.5(\mathbf{A}-\mathbf{D}) ; \times 5(\mathbf{F}$ and $\mathbf{G}) ; \times 1(\mathbf{I}) ; \times 5(\mathbf{J})$. 
Table 2

ECG characteristics of adult mice

\begin{tabular}{lccr}
\hline & Wild type & \multicolumn{2}{c}{ Myh6-CreTbx2tiffl } \\
& & $\begin{array}{c}\text { Normal } \\
(\boldsymbol{n}=\mathbf{4})\end{array}$ & $\begin{array}{c}\text { Preexcitation } \\
(\boldsymbol{n}=\mathbf{4})\end{array}$ \\
& $(\boldsymbol{n}=\mathbf{4})$ & $426.9 \pm 49.1$ & $435.3 \pm 23.4$ \\
HR (bpm) & $459 \pm 63.5$ & $34.6 \pm 4.0$ & $9.2 \pm 0.4^{\mathrm{A}}$ \\
PR (ms) & $32.9 \pm 1.0$ & $10.1 \pm 0.7$ & $17.2 \pm 4.4^{\mathrm{A}}$ \\
QRS (ms) & $10.1 \pm 1.1$ & $48.3 \pm 15.0$ & $51.0 \pm 13.6$ \\
QT (ms) & $42.7 \pm 15.0$ & $40.6 \pm 3.1$ & $39.3 \pm 11.2$ \\
QTC (ms) & $36.7 \pm 11.7$ & & \\
\hline
\end{tabular}

HR, heart rate. ${ }^{A} P<0.05$.

canal development. Bmp2-mediated signaling, essential for $\mathrm{AV}$ canal specification, can be detected as early as E8 in the precursors of the AV canal $(15,44)$. Here, it activates Tbx2, which subsequently, in concert with $T b \times 3$ and $M s \times 2$, suppresses chamber-specific gene expression and proliferation (16-18, 21, 45). Notch activity and Hey1/Hey2 (also known as Hesr1/Hesr2) in the adjacent developing chamber myocardium restrict the Bmp2/Tbx2 pathway to the developing AV canal $(19,20)$. Other components that have been implicated in AV canal (AV node) development include Nkx2.5, Tbx20, Tbx5, Gata4, and Foxn4 $(23-27,46,47)$. We propose that genetic or epigenetic mechanisms and environmental factors that affect these and other components of the regulatory network for $\mathrm{AV}$ canal development may cause dysmorphogenesis of the $\mathrm{AV}$ canal myocardium, acquisition of fast-conducting properties, and malformation of the annulus fibrosus (Figure 7). Consistently, microdeletions of BMP2 and Notch ligand, JAG$G E D 1$, have been associated with ventricular preexcitation as part of a syndrome of congenital defects $(48,49)$. Furthermore, deletion of the Alk3 receptor (Bmpr1a, activated by, among others, Bmp2) in the AV canal myocardium in mice results in accessory pathways and AV nodal defects $(7,38)$.

Mutations in LAMP2 $(50,51)$ and PRKAG2 $(35,52)$ are linked to the formation of accessory pathways. In these glycogen storage diseases, it has been proposed that glycogen toxicity causes annulus fibrosus thinning that underlies formation of accessory pathways $(35,52)$. However, in a cardiomyocyte-specific overexpression model of mutated PRKAG, accessory pathways only developed when the mutated PRKAG was overexpressed during development. When overexpression started in adulthood, glycogen storage disease and conduction system degeneration occurred but accessory pathways did not develop, suggesting that PRKAG may play a role in AV canal development $(36,37)$. Nevertheless, there is not an apparent link between PRKAG and the AV canal regulatory network.

\section{Methods}

\section{Transgenic mice}

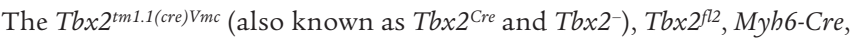
Tie2-Cre, Wnt1-Cre, and Cx30.2lacZ alleles have been described previously $(18,28,33,53-55)$. All mice were held on the FVB/N background, except for Cx30.2 LacZ mice, which were held on the C57BL/ 6 back-

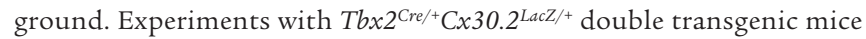
were performed in mixed FVB/N;C57BL/6 background. Animal experiments were performed in agreement with national and institutional guidelines and have been approved by the local Animal Experiments Committee, Academic Medical Center.

\section{Human embryos}

Human embryos were collected from medically induced abortions performed for various reasons at the Gynaecology Department of the Tartu University Hospital, Tartu, Estonia. Collection and use of the human embryonic material for research presented here were approved by the Medical Ethics Committees of the University of Tartu and the University of Amsterdam. Subsequent processing has been described previously (56).

\section{BrdU assay}

Pregnant female mice were injected intraperitoneally with $50 \mathrm{mg} \mathrm{BrdU} / \mathrm{kg}$ body weight (B5002, Sigma-Aldrich) dissolved in $0.9 \% \mathrm{NaCl}$. After 1 hour of BrdU exposure, the mice were killed by cervical dislocation. The embryos were isolated on ice-cold PBS and further processed for immunohistochemistry.

\section{Immunohistochemistry and in situ hybridization}

Embryos were fixed in $4 \%$ formaldehyde, embedded in paraplast, and sectioned at 7-8 $\mu \mathrm{m}$ for immunohistochemistry and $10-14 \mu \mathrm{m}$ for in situ hybridization. In situ hybridization was performed according to a previously described method (57). Probes have been described previously $(18,58-60)$. Rehydration, unmasking, blocking, and washing steps were

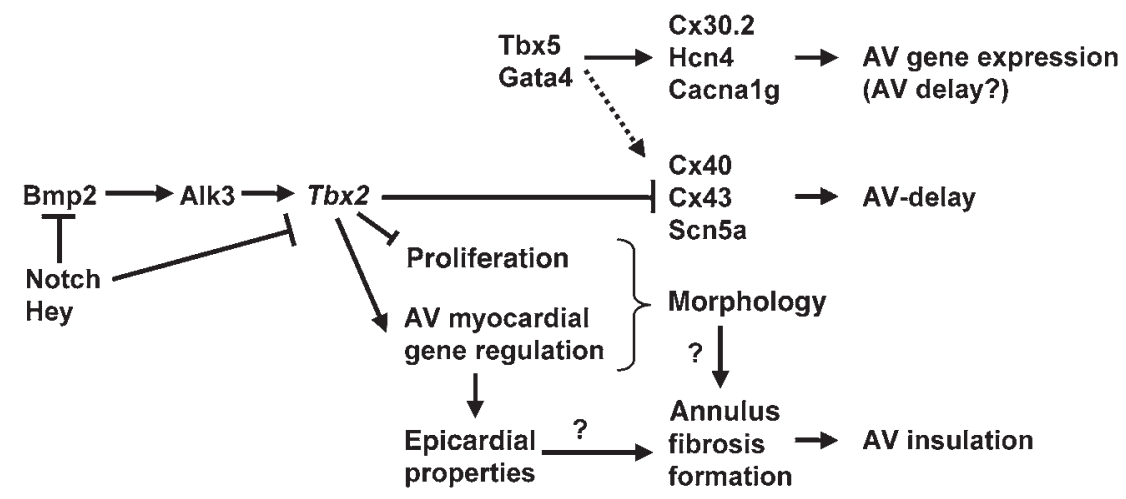

\section{Figure 7}

Model of the transcriptional regulatory network in the AV canal myocardium that depends on Tbx2 for correct patterning of the AV canal myocardium, formation of the annulus fibrosus, and generation of AV delay. 
performed according to the protocol of the tetramethylrhodamide-based amplification kit (PerkinElmer). Primary antibodies used for mouse sections were as follows: cardiac troponin I (cTnI) rabbit polyclonal (1:250; Hytest Ltd.); Tbx3 goat polyclonal (1:500; Santa Cruz Biotechnology Inc.); Cx40 mouse monoclonal (1:250; US Biological); $\mathrm{Cx} 43$ mouse monoclonal (1:250; BD Transduction Laboratories); Scn5a rabbit polyclonal (1:250; Alemone Labs); Nkx2.5 goat polyclonal (1:250; Santa Cruz Biotechnology Inc.); Hcn 4 goat polyclonal (1:250; Santa Cruz Biotechnology Inc.); BrdU rat polyclonal (1:600; AbD Serotec), and Cx30.2 rabbit polyclonal (1:200; gift from Klaus Willecke, Institut fuer Genetik, Rheinische Friedrichs-Wilhelm-Universitaet, Bonn, Germany). For apoptosis detection, we used the Cleaved Caspase-3 antibody (rabbit polyclonal, 1:250; Cell Signaling Technology). Primary antibodies used for human sections were as follows: Tbx2 mouse monoclonal (1:100; gift from Colin Goding, Ludwig Institute for Cancer Research, Oxford University, Oxford, United Kingdom), TBX3 goat polyclonal (1:250; Santa Cruz Biotechnology Inc.), and CX40 rabbit polyclonal (1:250; Santa Cruz Biotechnology Inc.). Secondary antibodies when using amplification were as follows: Biotinylated donkey anti-goat (1:250; Jackson ImmunoResearch Inc.), biotinylated goat antirabbit (1:250; DAKO), and biotinylated goat anti-mouse (1:250; DAKO). For visualization without the amplification step, secondary antibodies coupled to an Alexa Fluor fluorescent (1:250; Invitrogen) were used.

\section{$3 D$ reconstruction}

Image acquisition, processing, and subsequent $3 \mathrm{D}$ reconstruction was performed according to a previously described method (61). Serial sections were stained for $c \operatorname{TnI}$ (labeling all cardiomyocytes) and $C x 40$ and reconstructed.

\section{Preparation of the hearts and recording of electrograms and optical action potentials}

Adult hearts. ECGs were recorded for a period of 5 minutes during 1.5\% isoflurane anesthesia. Signals were averaged, after which RR, PQ, QRS, QT, and QTc were calculated.

For the local recordings, mice were anesthetized by an intraperitoneal injection of pentobarbital, after which the heart was excised, cannulated, mounted on a Langendorff perfusion setup, and perfused at $37^{\circ} \mathrm{C}$ with Tyrode's solution $(128 \mathrm{mmol} / \mathrm{l} \mathrm{NaCl}, 4.7 \mathrm{mmol} / \mathrm{l} \mathrm{KCl}, 1.45 \mathrm{mmol} / \mathrm{l} \mathrm{CaCl} 2,0.6 \mathrm{mmol} / 1$ $\mathrm{MgCl}_{2}, 27 \mathrm{mmol} / 1 \mathrm{NaHCO}, 0.4 \mathrm{mmol} / 1 \mathrm{NaH}_{2} \mathrm{PO}_{4}$, and $11 \mathrm{mmol} / \mathrm{l}$ glucose $\left[\mathrm{pH}\right.$ maintained at 7.4 by equilibration with a mixture of $95 \% \mathrm{O}_{2}$ and $\left.5 \% \mathrm{CO}_{2}\right]$ ).
After that, the hearts were incubated in $10 \mathrm{ml}$ Tyrode's solution containing $15 \mu \mathrm{M}$ Di-4 ANEPPS and subsequently placed in a optical mapping setup. Excitation light was provided by a 5 -watt power LED (filtered $510 \pm 20 \mathrm{~nm}$ ). Fluorescence (filtered $>610 \mathrm{~nm}$ ) was transmitted through a tandem lens system on CMOS sensor $(100 \times 100$ elements; MICAM Ultima). Activation patterns were measured during sinus rhythm and ventricular and atrial pacing at a basic cycle length of $120 \mathrm{~ms}$ (twice the diastolic stimulation threshold). The effective refractory period of the $\mathrm{AV}$ node was determined by atrial pacing and reducing the coupling interval of a premature stimulus (after trains of 10 stimuli at basic cycle length of $120 \mathrm{~ms}$ ) in steps of $5 \mathrm{~ms}$ until activation of the ventricle failed. Optical action potentials were analyzed with custom software.

Fetal hearts. Hearts were removed from the embryos and incubated for 5 minutes with Tyrode's solution containing $5 \mu \mathrm{M}$ Di- 4 ANEPPS at $37^{\circ} \mathrm{C}$. After incubation, fetal hearts were superfused with Tyrode's solution and placed on the stage of a custom-made inverted microscope setup for recording optical signals.

\section{Statistics}

Group comparisons were performed using ANOVA. Values are given as mean \pm SEM. Genotype and phenotype frequencies were tested with a $\chi^{2}$ test. A $P$ value of 0.05 was considered statistically significant.

\section{Acknowledgments}

We thank K. Willecke, University of Bonn, for providing the $C \times 30.2^{\mathrm{LacZ} / L a c Z}$ mice and Brian Black, University of California, San Francisco, for providing the Mef2c-AHF-Cre mice. This work was supported by grants from the Netherlands Heart Foundation (2010B205 and 2008B062 to V.M. Christoffels and R. Coronel) and the European Community's Sixth Framework Programme contract ("HeartRepair" LSHM-CT-2005-018630 to V.M. Christoffels and A.F.M. Moorman).

Received for publication July 14, 2010, and accepted in revised form November 1, 2010.

Address correspondence to: Vincent M. Christoffels, Heart Failure Research Center, Academic Medical Center, Meibergdreef 15, 1105 AZ Amsterdam, The Netherlands. Phone: 31.20.566.7821; Fax: 31.20.697.6177; E-mail: v.m.christoffels@amc.uva.nl.
1. Munger TM, et al. A population study of the natural history of Wolff-Parkinson-White syndrome in Olmsted County, Minnesota, 1953-1989. Circulation. 1993;87(3):866-873.

2. Packard JM, Graettinger JS, Graybiel A. Analysis of the electrocardiograms obtained from 1000 young healthy aviators; ten year follow-up. Circulation. 1954;10(3):384-400.

3. Centurion OA, Shimizu A, Isomoto S, Konoe A. Mechanisms for the genesis of paroxysmal atrial fibrillation in the Wolff Parkinson-White syndrome: intrinsic atrial muscle vulnerability vs. electrophysiological properties of the accessory pathway. Europace. 2008;10(3):294-302.

4. Basso C, Corrado D, Rossi L, Thiene G. Ventricular preexcitation in children and young adults: atrial myocarditis as a possible trigger of sudden death. Circulation. 2001;103(2):269-275.

5. Wood FC, Wolferth CC, Geckeler GD. Histologic demonstration of accessory muscular connections between auricle and ventricle in a case of short P-R interval and prolonged QRS complex. Am Heart J. 1943;25(4):454-462.

6. Hahurij ND, et al. Accessory atrioventricular myocardial connections in the developing human heart: relevance for perinatal supraventricular tachycar- dias. Circulation. 2008;117(22):2850-2858.

7. Stroud DM, et al. Abnormal conduction and morphology in the atrioventricular node of mice with atrioventricular canal-targeted deletion of Alk3/Bmpr1a receptor. Circulation. 2007;116(22):2535-2543.

8. Anderson RH, Ho SY, Gillette PC, Becker AE. Mahaim, Kent and abnormal atrioventricular conduction. Cardiovasc Res. 1996;31(4):480-491.

9. Kolditz DP, et al. Epicardium-derived cells in development of annulus fibrosis and persistence of accessory pathways. Circulation. 2008;117(12):1508-1517.

10. Tallini YN, et al. Imaging cellular signals in the heart in vivo: Cardiac expression of the high-signal Ca2+ indicator GCaMP2. Proc Natl Acad Sci U S A. 2006;103(12):4753-4758.

11. James TN. Sudden death in babies: new observations in the heart. Am J Cardiol. 1968;22(4):479-506.

12. McGuire MA, et al. Atrioventricular junctional tissue. Discrepancy between histological and electrophysiological characteristics. Circulation. 1996;94(3):571-577.

13. Yanni J, Boyett MR, Anderson RH, Dobrzynski H. The extent of the specialized atrioventricular ring tissues. Heart Rhythm. 2009;6(5):672-680.

14. Aanhaanen WT, et al. Developmental origin, growth, and three-dimensional architecture of the atrioventricular conduction axis of the mouse heart. Circ Res. 2010;107(6):728-736.

15. Ma L, Lu MF, Schwartz RJ, Martin JF. Bmp2 is essential for cardiac cushion epithelial-mesenchymal transition and myocardial patterning. Development. 2005;132(24):5601-5611.

16. Habets PEMH, et al. Cooperative action of Tbx2 and Nkx2.5 inhibits ANF expression in the atrioventricular canal: implications for cardiac chamber formation. Genes Dev. 2002;16(10):1234-1246.

17. Harrelson $Z$, et al. Tbx2 is essential for patterning the atrioventricular canal and for morphogenesis of the outflow tract during heart development. Development. 2004;131(20):5041-5052.

18. Aanhaanen WT, et al. The Tbx $2+$ primary myocardium of the atrioventricular canal forms the atrioventricular node and the base of the left ventricle. Circ Res. 2009;104(1):1267.

19. Kokubo H, Tomita-Miyagawa S, Hamada Y, Saga Y. Hesr1 and Hesr2 regulate atrioventricular boundary formation in the developing heart through the repression of Tbx2. Development. 2007;134(4):747-755.

20. Rutenberg JB, Fischer A, Jia H, Gessler M, Zhong TP, Mercola M. Developmental patterning of the cardiac atrioventricular canal by Notch and Hairy-related transcription factors. Development. 
2006;133(21):4381-4390.

21. Boogerd KJ, et al. Msx1 and Msx2 are functional interacting partners of T-box factors in the regulation of connexin 43. Cardiovasc Res. 2008;78(3):485-493.

22. Chen YH, Ishii M, Sucov HM, Maxson RE Jr. Msx1 and Msx2 are required for endothelialmesenchymal transformation of the atrioventricular cushions and patterning of the atrioventricular myocardium. BMC Dev Biol. 2008;8:75.

23. Jay PY, et al. Nkx2-5 mutation causes anatomic hypoplasia of the cardiac conduction system. J Clin Invest. 2004;113(8):1130-1137.

24. Munshi NV, et al. Cx30.2 enhancer analysis identifies Gata4 as a novel regulator of atrioventricular delay. Development. 2009;136(15):2665-2674.

25. Moskowitz IPG, et al. The T-Box transcription factor Tbx5 is required for the patterning and maturation of the murine cardiac conduction system. Development. 2004;131(16):4107-4116.

26. Pashmforoush $\mathrm{M}$, et al. Nkx2-5 pathways and congenital heart disease; loss of ventricular myocyte lineage specification leads to progressive cardiomyopathy and complete heart block. Cell. 2004;117(3):373-386.

27. Christoffels VM, Smits GJ, Kispert A, Moorman AF. Development of the pacemaker tissues of the heart. Circ Res. 2010;106(2):240-254

28. Kreuzberg MM, et al. Connexin30.2 containing gap junction channels decelerate impulse propagation through the atrioventricular node. Proc Natl Acad Sci U S A. 2006;103(15):5959-5964.

29. Wessels A, Markman MWM, Vermeulen JLM, Anderson RH, Moorman AFM, Lamers WH. The development of the atrioventricular junction in the human heart. Circ Res. 1996;78(1):110-117.

30. Nakamura T, Colbert MC, Robbins J. Neural crest cells retain multipotential characteristics in the developing valves and label the cardiac conduction system. Circ Res. 2006;98(12):1547-1554.

31. Snarr BS, Wirrig EE, Phelps AL, Trusk TC, Wessels A. A spatiotemporal evaluation of the contribution of the dorsal mesenchymal protrusion to cardiac development. Dev Dyn. 2007;236(5):1287-1294.

32. de Lange FJ, et al. Lineage and morphogenetic analysis of the cardiac valves. Circ Res. 2004;95(6):645-654

33. Kisanuki YY, Hammer RE, Miyazaki J, Williams SC, Richardson JA, Yanagisawa M. Tie2-Cre transgenic mice: a new model for endothelial cell-lineage analysis in vivo. Dev Biol. 2001;230(2):230-242.

34. Peters NS, Rowland E, Bennett JG, Green CR, Anderson RH, Severs NJ. The Wolff-ParkinsonWhite syndrome: the cellular substrate for conduction in the accessory atrioventricular pathway. Eur Heart J. 1994;15(7):981-987.
35. Arad M, et al. Transgenic mice overexpressing mutant PRKAG2 define the cause of Wolff-Parkinson-White syndrome in glycogen storage cardiomyopathy. Circulation. 2003;107(22):2850-2856.

36. Wolf CM, et al. Reversibility of PRKAG2 glycogenstorage cardiomyopathy and electrophysiological manifestations. Circulation. 2008;117(2):144-154.

37. Sidhu JS, et al. Transgenic mouse model of ventricular preexcitation and atrioventricular reentrant tachycardia induced by an AMP-activated protein kinase lossof-function mutation responsible for Wolff-Parkinson-White syndrome. Circulation. 2005;111(1):21-29.

38. Gaussin V, et al. Alk3/Bmpr1a receptor is required for development of the atrioventricular canal into valves and annulus fibrosus. Circ Res. 2005;97(3):219-226.

39. Davies JK, et al. Characterization of the role of gamma2 R531G mutation in AMP-activated protein kinase in cardiac hypertrophy and Wolff-Parkinson-White syndrome. Am J Physiol Heart Circ Physiol. 2006;290(5):H1942-H1951.

40. Banerjee SK, et al. A PRKAG2 mutation causes biphasic changes in myocardial AMPK activity and does not protect against ischemia. Biochem Biophys Res Commun. 2007;360(2):381-387

41. Calkins H, et al. Radiofrequency catheter ablation of accessory atrioventricular connections in 250 patients. Abbreviated therapeutic approach to Wolff-Parkinson-White syndrome. Circulation. 1992;85(4):1337-1346.

42. OuYang W, Hemmings HC Jr. Isoform-selective effects of isoflurane on voltage-gated $\mathrm{Na}+$ channels. Anesthesiology. 2007;107(1):91-98.

43. Basson CT. A molecular basis for Wolff-Parkinson-White syndrome. $N$ Engl J Med. 2001; 344(24):1861-1864.

44. Yamada M, Revelli JP, Eichele G, Barron M, Schwartz RJ. Expression of chick Tbx-2, Tbx-3, and Tbx-5 genes during early heart development: evidence for BMP2 induction of Tbx2. Dev Biol. 2000;228(1):95-105.

45. Christoffels VM, Hoogaars WMH, Tessari A, Clout DEW, Moorman AFM, Campione M. T-box transcription factor $\mathrm{Tbx} 2$ represses differentiation and formation of the cardiac chambers. Dev Dyn. 2004;229(4):763-770.

46. Singh R, et al. Tbx20 interacts with smads to confine tbx 2 expression to the atrioventricular canal. Circ Res. 2009;105(5):442-452.

47. Chi NC, et al. Foxn 4 directly regulates tbx2b expression and atrioventricular canal formation. Genes Dev. 2008;22(6):734-739.

48. Le GL, et al. A $8.26 \mathrm{Mb}$ deletion in $6 \mathrm{q} 16$ and a $4.95 \mathrm{Mb}$ deletion in $20 \mathrm{p} 12$ including JAG 1 and BMP2 in a patient with Alagille syndrome and
Wolff-Parkinson-White syndrome. Eur J Med Genet. 2008;51(6):651-657.

49. Lalani SR, et al. 20p12.3 microdeletion predisposes to Wolff-Parkinson-White syndrome with variable neurocognitive deficits. JMed Genet. 2009;46(3):168-175.

50. Yang $Z$, et al. LAMP2 microdeletions in patients with Danon disease. Circ Cardiovasc Genet. 2010; 3(2):129-137

51. Bui YK, Renella P, Martinez-Agosto JA, Verity A, Madikians A, Alejos JC. Danon disease with typical early-onset cardiomyopathy in a male: focus on a novel LAMP-2 mutation. Pediatr Transplant. 2008;12(2):246-250.

52. Gollob MH, et al. Identification of a gene responsible for familial Wolff-Parkinson-White syndrome. NEngl J Med. 2001;344(24):1823-1831.

53. Wakker V, Brons JF, Aanhaanen WT, van Roon MA, Moorman AF, Christoffels VM. Generation of mice with a conditional null allele for Tbx2. Genesis. 2010;48(3):195-199.

54. Agah R, Frenkel PA, French BA, Michael LH, Overbeek PA, Schneider MD. Gene recombination in postmitotic cells. Targeted expression of Cre recombinase provokes cardiac-restricted, site-specific rearrangement in adult ventricular muscle in vivo. J Clin Invest. 1997;100(1):169-179.

55. Danielian PS, Muccino D, Rowitch DH, Michael SK, McMahon AP. Modification of gene activity in mouse embryos in utero by a tamoxifen-inducible form of Cre recombinase. Curr Biol. 1998;8(24):1323-1326.

56. Sizarov A, Anderson RH, Christoffels VM, Moorman AF. Three-dimensional and molecular analysis of the venous pole of the developing human heart. Circulation. 2010;122(8):798-807.

57. Moorman AFM, Houweling AC, de Boer PAJ, Christoffels VM. Sensitive nonradioactive detection of mRNA in tissue sections: novel application of the whole-mount in situ hybridization protocol. J Histochem Cytochem. 2001;49(1):1-8.

58. Mommersteeg MTM, et al. Molecular pathway for the localized formation of the sinoatrial node. Circ Res. 2007;100(3):354-362.

59. Hoogaars WM, et al. Tbx3 controls the sinoatrial node gene program and imposes pacemaker function on the atria. Genes Dev. 2007;21(9):1098-1112.

60. Kruzynska-Frejtag A, et al. Periostin is expressed within the developing teeth at the sites of epithelial-mesenchymal interaction. Dev Dyn. 2004; 229(4):857-868

61. Soufan AT, Ruijter JM, van den HoffMJB, de Boer PAJ, Hagoort J, Moorman AFM. Three-dimensional reconstruction of gene expression patterns during cardiac development. Physiol Genomics. 2003;13(3):187-195. 